\title{
Steric control of the excited state intramolecular proton transfer in 3-hydroxyquinolones: steady-state and time- resolved fluorescence study
}

Dmytro A. Yushchenko, Volodymyr V. Shvadchak, Andrey S. Klymchenko, Guy Duportail, Vasyl G. Pivovarenko and Yves Mély

\section{Supporting information}

Time-resolved decay curves of dyes HPQ, MPQ, HMQ, MMQ in dimethylformamide (DMF), ethyl acetate (EtOAc), acetonitrile (MeCN). 

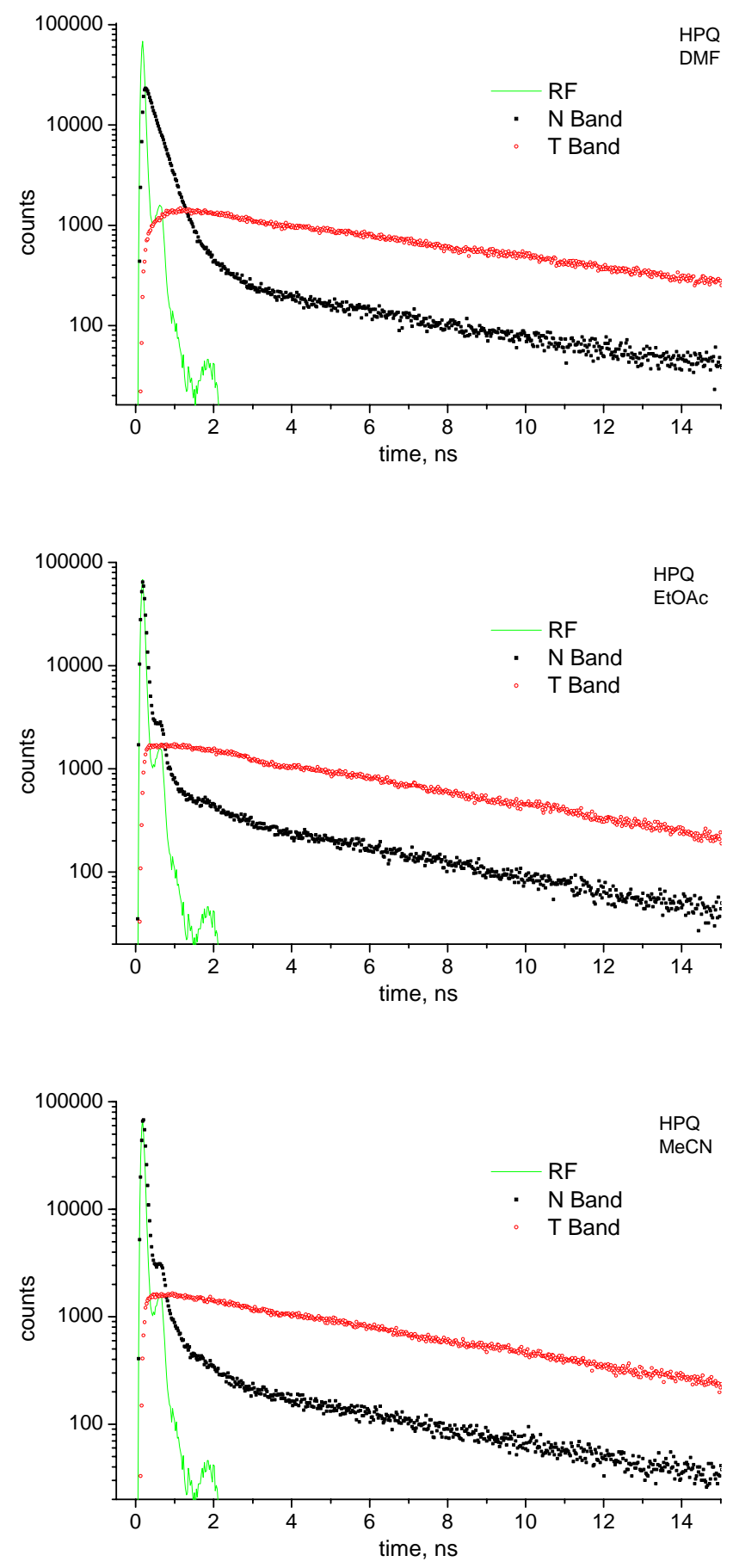

Fig S1. Fluorescence decay data for HPQ in DMF, EtOAc and MeCN.

Fluorescence was recorded at $420 \mathrm{~nm}$ for the $\mathrm{N}^{*}$ band and at $540 \mathrm{~nm}$ for the $\mathrm{T}^{*}$ band. Excitation wavelength was $320 \mathrm{~nm}$. 

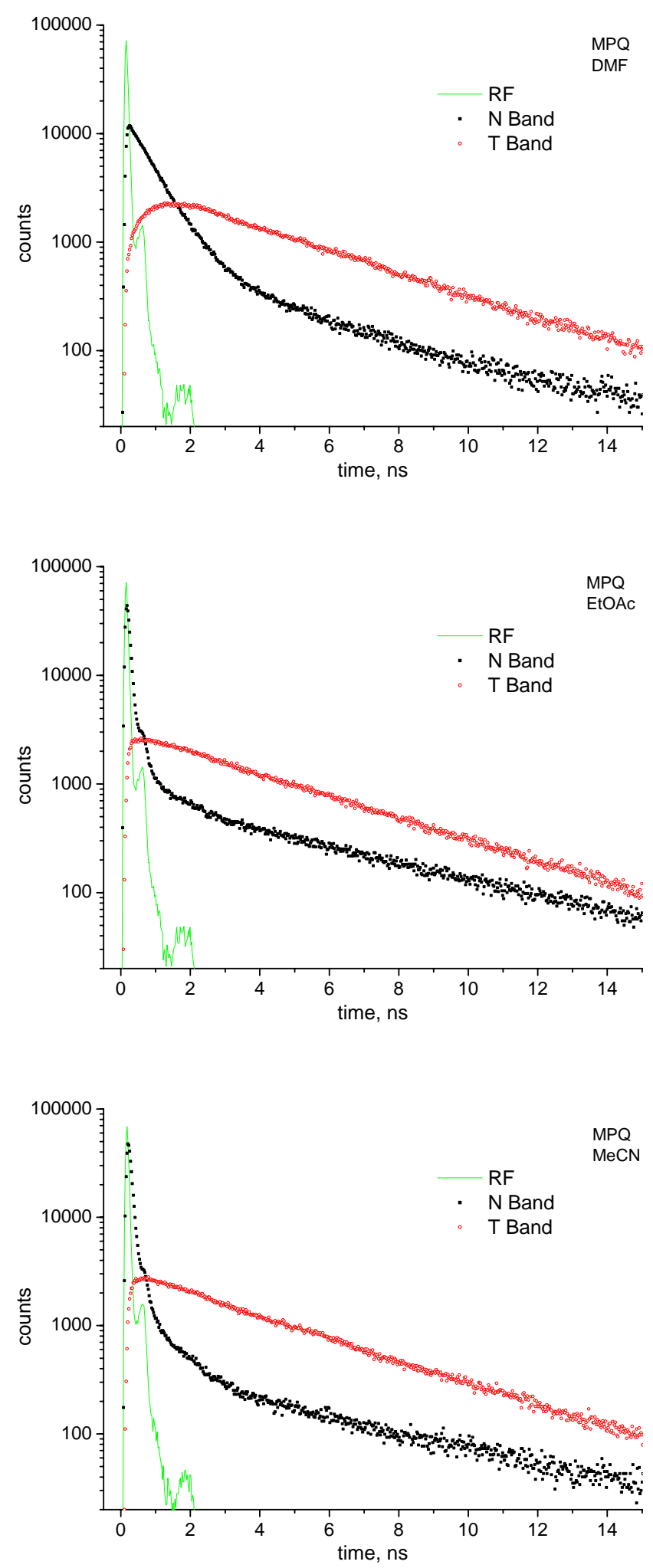

Fig S2. Fluorescence decay data for MPQ in DMF, EtOAc and MeCN. Fluorescence was recorded at $400 \mathrm{~nm}$ for the $\mathrm{N}^{*}$ band and at $550 \mathrm{~nm}$ for the $\mathrm{T}^{*}$ band. Excitation wavelength was $320 \mathrm{~nm}$. 

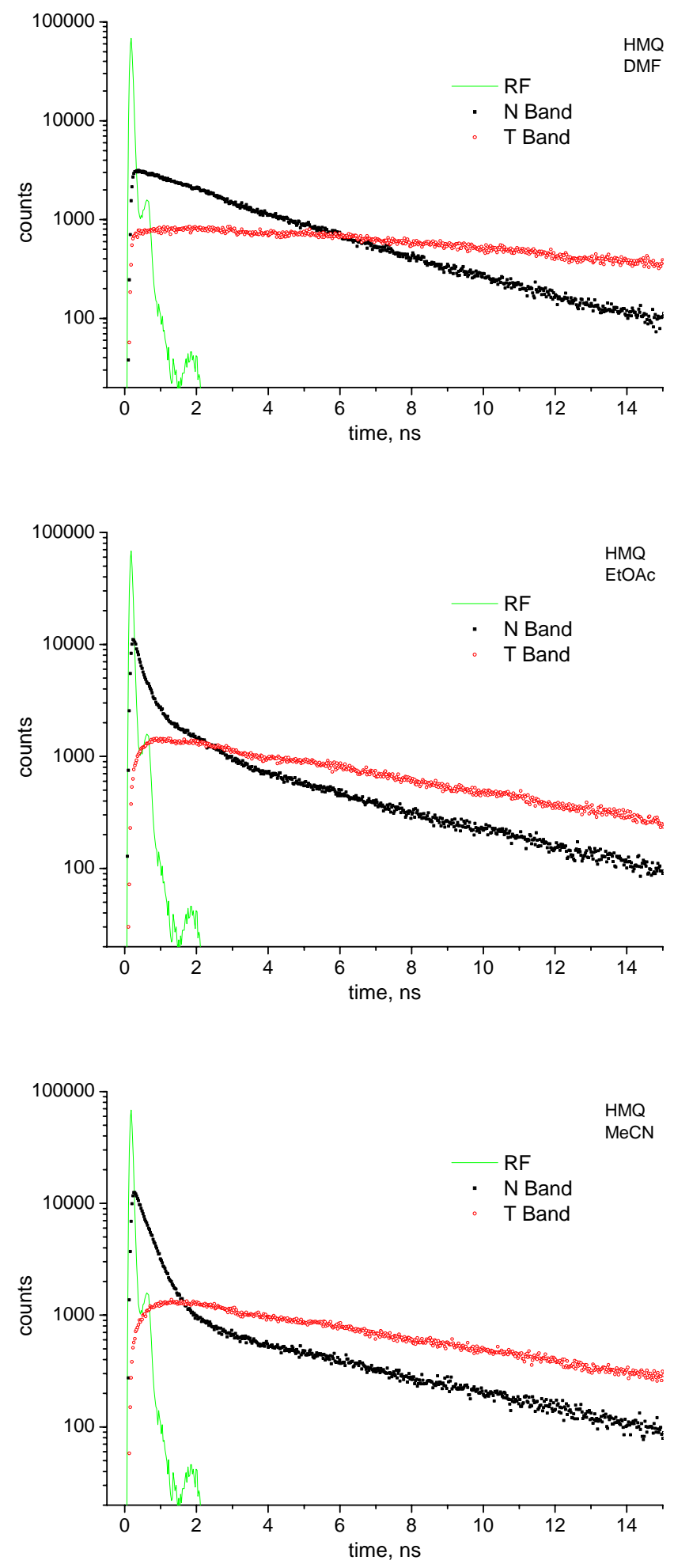

Fig S3. Fluorescence decay data for HMQ in DMF, EtOAc and MeCN

Fluorescence was recorded at $390 \mathrm{~nm}$ for the $\mathrm{N}^{*}$ band and at $460 \mathrm{~nm}$ for the $\mathrm{T}^{*}$ band. Excitation wavelength was $320 \mathrm{~nm}$. 

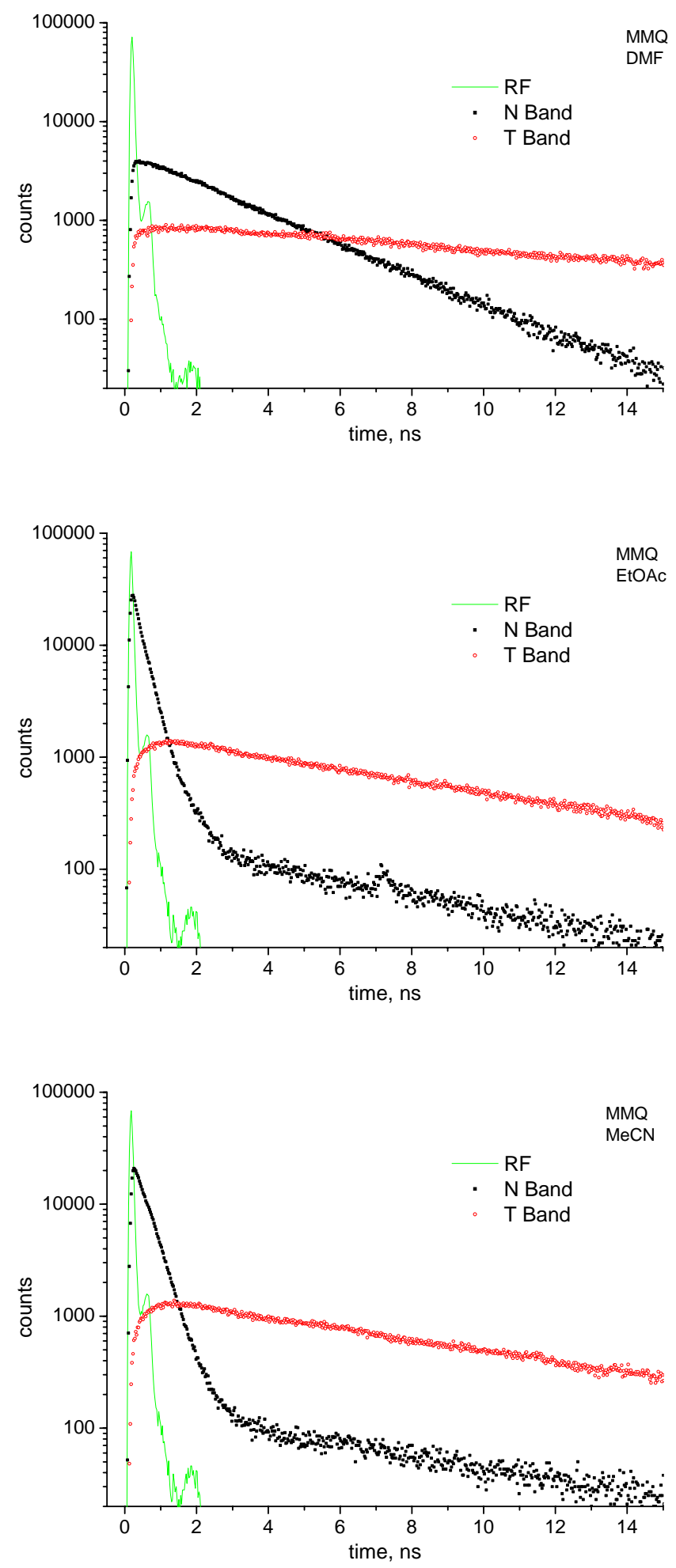

Fig S4. Fluorescence decay data for MMQ in DMF, EtOAc and MeCN.

Fluorescence was recorded at 390-400 $\mathrm{nm}$ for the $\mathrm{N}^{*}$ band and at $460 \mathrm{~nm}$ for the $\mathrm{T}^{*}$ band. Excitation wavelength was $320 \mathrm{~nm}$. 